\title{
Entre percursos formativos e comunidades de aprendentes: políticas curriculares para a educação integral no Brasil
}

\author{
Roberto Rafael Dias Silva *
}

\section{Resumo}

O presente artigo examina os regimes de implementação das políticas curriculares de ampliação da jornada escolar desenvolvidas nos Estados do Rio Grande do Sul e de Santa Catarina. Ao inscrever-se no campo dos Estudos Curriculares, procurou-se compreender seus processos de seleção e organização do conhecimento escolar. As políticas examinadas são implementadas a partir de duas noções distintas e complementares, quais sejam: percursos formativos e comunidades de aprendentes. Constatou-se, através de uma análise textual dos documentos curriculares orientadores das referidas políticas, uma significativa preocupação com os processos de seleção dos conhecimentos escolares a serem ensinados; todavia, ainda se notaram algumas dificuldades para indicar os critérios orientadores para as referidas escolhas, bem como as racionalidades pedagógicas que justificam sua implementação.

Palavras-chave: Políticas curriculares. Educação Integral. Conhecimento escolar.

* Doutor em Educação pela Universidade do Vale do Rio dos Sinos (UNISINOS). Professor do Programa de PósGraduação em Educação da Universidade do Vale do Rio dos Sinos (UNISINOS). 


\section{Introdução}

Tempo livre como o tempo de estudo, pensamento e exercício é o tempo que é separado da vida produtiva, é tempo em que o labor e o trabalho como atividades econômicas são colocados a uma distância (SIMONS; MASSCHELEIN, 2014, p. 162).

Os escritos filosóficos de Simons e Masschelein, recentemente, têm sido muito relevantes para uma reflexão sobre a escolarização enquanto uma tarefa pública. Em sua perspectiva, valendo-se de um conjunto diversificado de pensadores contemporâneos, os autores afirmam ser necessária a fabricação de novos exercícios de pensamento acerca das instituições escolares e de seu potencial formativo. Aproximando-se dessa questão, retomam uma das origens da palavra "escola" (skholé, no grego), ligando-a ao sentido de "tempo livre", entendido como "um tempo de pensamento, estudo e exercício" (SIMONS; MASSCHELEIN, 2014, p. 160). Para os autores, o tempo da escolarização não seria destinado a objetivos pré-fixados, nem mesmo a noções recorrentes, como aprendizagem ou ludicidade. Todavia, ressaltam que a escola não seria um "tempo sem destino e sem objetivo ou fim" (SIMONS; MASSCHELEIN, 2014, p. 161).

Assim, Simons e Masschelein buscam construir uma argumentação acerca do necessário reconhecimento da escola como um espaço que "suspende" outras finalidades, distanciando-se das vidas cidadãs ou economicamente produtivas, tão defendidas nas políticas de nosso tempo. O uso do verbo "suspender" torna-se relevante para esta reflexão, visto que não significa abandonar ou excluir tais objetivos das dinâmicas formativas atinentes a esta instituição. De forma complementar, afirmam a necessidade de movimentos de "profanação", como um exercício de produção de novos sentidos em comum. Em tais condições, "as coisas são, assim, desconectadas do uso sagrado ou estabelecido da velha geração na sociedade, mas ainda não apropriadas por estudantes ou alunos como representantes da nova geração. A escola profana/skholé funciona como uma espécie de lugar comum, onde nada é compartilhado, mas tudo pode ser compartilhado" (SIMONS; MASSCHELEIN, 2014, p. 163).

Ao longo do presente artigo, apresentaremos alguns exercícios investigativos, derivados de nossas atividades de pesquisa sobre as políticas curriculares recentemente implementadas no contexto brasileiro. Particularmente, para fins deste texto, interessa-nos colocar em exame as políticas recentemente implementadas pelos Estados de Santa Catarina e do Rio Grande do Sul, situados no Sul do país. Mais que simplesmente optar pela ampliação da jornada escolar, ambas as políticas são implementadas a partir de duas noções distintas e complementares, quais sejam: percursos formativos e comunidades de aprendentes. Constatamos, através de uma análise textual dos documentos curriculares 
orientadores das referidas políticas, uma significativa preocupação com os processos de seleção dos conhecimentos escolares a serem ensinados; todavia, notamos também dificuldades para indicar os critérios orientadores para as referidas escolhas, bem como as racionalidades pedagógicas que justificam sua implementação.

Do ponto de vista teórico, cabe reiterar que o presente estudo se inscreve no campo dos Estudos Curriculares, buscando interações com a sociologia crítica do currículo por meio da aproximação com leituras das teorizações sociais contemporâneas. Assim sendo, organizamos o presente texto em três seções. Na primeira seção, apresentamos um diagnóstico das relações entre conhecimento e formação humana, servindo-nos das elaborações advindas dos Estudos Curriculares. A seguir, na segunda seção, produzimos uma breve revisão dos estudos que focalizam as experiências de ampliação da jornada escolar no contexto brasileiro. Ao final, na terceira seção, desenvolveremos as análises das políticas curriculares implementadas no contexto dos Estados de Santa Catarina e do Rio Grande do Sul ao longo da última década.

\section{Conhecimento e formação humana: um exame crítico}

Ao longo dessa seção, pretendemos apresentar alguns dos modos pelos quais as questões atinentes ao conhecimento e à formação humana, em produtiva aproximação, são problematizadas por diferentes tradições no âmbito dos Estudos Curriculares. Em elaboração recente, Pacheco (2014) propõe-se a produzir uma reflexão panorâmica sobre a questão do conhecimento na atualidade, em sua relação com a formação humana. O ponto central de sua argumentação é a institucionalização da escola, a partir de sua constituição histórica. Com tal processo de institucionalização, ao longo do tempo, "pretende-se, acima de tudo, impor um modelo de conhecimento construído a partir de interesses muito diversos, que permita estabelecer elos entre as gerações” (PACHECO, 2014, p. 7). A escola, enquanto arranjo institucional, ainda na percepção de Pacheco (2014, p. 7), "é a história dessa operação em torno do conhecimento". A seleção, a organização e as possibilidades de transmissão cultural de determinados saberes caracterizam a tarefa pública da escolarização.

Enquanto invenção do projeto de formação escolar, engendrados a partir de determinadas tecnologias políticas, os currículos escolares assumem centralidade nestes espaços de educação e de formação. Por diferentes percursos, no âmbito dos currículos encontramos a legitimação de formas específicas de conhecimento, socialmente reconhecidas e valorizadas, cuja seleção é desenvolvida no interior de um território político. Em razão disso, lembra-nos Pacheco (2014, p. 8): 
O corpus do conhecimento escolar é, por conseguinte, a longa tradição da existência de propostas curriculares, elegendo-se, nesta seleção, organização e transformação, o que as circunstâncias têmporo-espaciais ditam como sendo as mais válidas. Acrescentamse, ainda; as circunstâncias econômicas, sociais, culturais e ideológicas.

Em outras palavras, pensar a constituição dos conhecimentos escolares implicaria uma leitura abrangente (SILVA; PEREIRA, 2013).

Do ponto de vista dos Estudos Curriculares, a potencialidade analítica dessa questão poderia ser evidenciada por distintas tradições. Young (2013), em uma perspectiva realista-social, apresenta a relevância social e epistemológica dos conhecimentos a serem ensinados nas escolas. Mais que simplesmente transmitir formas estáticas de conteúdos passados, o sociólogo defende que o propósito dos currículos seria "capacitar a próxima geração de modo que ela possa construir sobre esse conhecimento, criando um conhecimento novo, pois é assim que as sociedades humanas progridem e os indivíduos se desenvolvem” (YOUNG, 2013, p. 3).

De acordo com o sociólogo britânico, a tarefa dos Estudos Curriculares seria, então, "partir não do aluno como aprendiz, mas do direito do aluno ou do seu acesso ao conhecimento" (YOUNG, 2013, p. 18). Essa opção analítica sugere que a interrogação central dos currículos - "qual conhecimento?”seja potencializada tanto epistemologicamente quanto no âmbito da justiça social. Essa perspectiva tem sido nomeada como "realismo social", uma vez que, conforme Moore (2012), busca produzir alternativas aos dois modos convencionais de pensar a questão do conhecimento no âmbito da sociologia da educação, a saber: o positivismo e o construtivismo social.

Sob outras condições argumentativas, Popkewitz (2009, p. 19) auxilia-nos a elaborar uma crítica política da escolarização, alicerçada em sua "epistemologia social”. Para pensar o conhecimento na escola, essa forma de abordagem leva-nos a pensar sobre "as políticas da razão como práticas históricas regidas pela reflexão e a ação". Inspirado no conceito foucaultiano de governamentalidade, o autor problematiza as políticas de reforma da escolarização, a partir de uma ênfase na noção de aprendizagem permanente. Tal noção, ao privilegiar as competências dos aprendizes, "enfoca a atual seleção dos conteúdos, na qual as ferramentas de tradução e inscrição do currículo estão relacionadas com os modos de vida que têm pouco a ver com as disciplinas escolares propriamente ditas" (POPKEWITZ, 2009, p. 129). Os currículos escolares deste século, de acordo com o autor, enfatizam cada vez mais as questões ligadas à conduta dos aprendentes. Isto também evidenciaria a relevância social e pedagógica de pensar o conhecimento na escola.

De maneira objetiva, então, o campo de relações estabelecido entre conhecimento e formação humana, sobretudo no que tange à seleção dos conhecimentos a serem ensinados, apresenta-se como 
foco importante para os Estudos Curriculares ${ }^{1}$. De acordo com Forquin (2011, 714-715), em um exercício de sistematização, pensar a questão da seleção implica a "escolha discriminativa no interior de um conjunto explicitamente identificável e inventariável de coisas, sinais ou pessoas "disponíveis"”. Em torno desse aspecto, importa assinalar a noção de "transmissão cultural", caracterizada no âmbito escolar por processos de seleção e reorganização.

Isso significa dizer que a educação não transmite $a$ cultura, considerada como um patrimônio simbólico unitário e imperiosamente coerente. Nem sequer diremos que ela transmite fielmente uma cultura ou culturas (no sentido dos etnólogos e sociólogos): ela transmite, no máximo, algo da cultura, elementos de cultura, entre os quais não há forçosamente homogeneidade, que podem provir de fontes diversas, ser épocas diferentes, obedecer a princípios de produção e lógicas de desenvolvimento heterogêneos e não recorrer aos mesmos procedimentos de legitimação. (FORQUIN, 1993, p. 15).

Ao supormos que a escola transmite algo da cultura, selecionado a partir de processos heterogêneos, podemos reconhecer que a seleção dos conhecimentos escolares ocorre em um território político. Em razão disso, o sociólogo francês instiga-nos a considerar que "o pensamento pedagógico contemporâneo não pode se esquivar de uma reflexão sobre a questão da cultura e dos elementos culturais dos diferentes tipos de escolhas educativas, sob pena de cair na superficialidade" (FORQUIN, 1993, p. 10). Ampliaremos o escopo dessa argumentação a seguir, ao direcionarmos nossa atenção às políticas contemporâneas de ampliação da jornada escolar em implementação no contexto brasileiro.

\section{Políticas curriculares e ampliação da jornada escolar: dilemas e perspectivas}

Acerca das políticas e decisões curriculares, no contexto brasileiro, Moreira (2012, p. 183) considera que poderiam ser promovidas a partir de dois princípios básicos, quais sejam: "a revalorização do conhecimento escolar e a importância dos fenômenos culturais mais amplos". A combinação desses princípios, de acordo com o pesquisador, poderia ser importante para "garantir a formulação de currículos inovadores, capazes de contribuir para a construção de uma escola de qualidade em nosso país" (MOREIRA, 2012, p. 187). O primeiro princípio remete à relevância do conhecimento escolar, geralmente negligenciado nas políticas curriculares atuais. O segundo princípio, de forma complementar e indissociável, defende o foco nos "fenômenos culturais contemporâneos, como globalização, homogeneização cultural, diversidade cultural, pluralismo cultural, hibridismo, diferença, política de identidades" (MOREIRA, 2012, p. 186). Nas palavras do autor, "insisto que ao 
indispensável foco no conhecimento escolar se associe o inadiável foco na cultura" (MOREIRA, 2012, p. 187).

Ao examinarmos atentamente as políticas contemporâneas de escolarização, nos contextos nacional e internacional, é possível perceber uma tendência no incentivo de práticas de ampliação da jornada escolar (CATARSI, 2004; CAVALIERE, 2007; CABALLO; CARIDE; GRADAILLE, 2012). Geralmente, tais políticas posicionam a ampliação do tempo escolar em uma perspectiva de ressignificação das culturas escolares, tanto no que se refere a uma multiplicação de programas de proteção social quanto no que se refere a deslocamentos nos sentidos da qualidade pedagógica dos processos formativos na Educação Básica. Do ponto de vista teórico, destacamos que essa problemática atravessa a produção analítica de diferentes teorizações, assim como de contextos múltiplos e diferenciados (COELHO, 2009; MOLL, 2012).

No contexto brasileiro, ainda que a emergência da temática seja decorrente dos movimentos de renovação pedagógica da primeira metade do século XX (TEIXEIRA, 1978), nas últimas duas décadas notamos um movimento de consolidação da temática da ampliação do tempo escolar (CAVALIERE, 2007; FELÍCIO, 2012), movimento passível de ser observado tanto na literatura contemporânea quanto no ordenamento curricular das escolas brasileiras. Tal consolidação, de forma geral, é produzida sob as condições de atendimento aos delineamentos históricos da educação brasileira, sobretudo no que tange ao artigo 34 da Lei no 9.394, de 20 de dezembro de 1996, que versa sobre a possibilidade de ampliação dos tempos escolares na Educação Básica. Atualmente, com a multiplicação de novos programas governamentais, intensificaram-se iniciativas nessa direção, sobretudo com ações multissetoriais como os programas Mais Educação, Segundo Tempo ou Ensino Médio Inovador, entre outros. De forma a reforçar esse cenário, destacamos também que o novo Plano Nacional de Educação (PNE) encaminha em sua meta 6 a ampliação da jornada escolar em 50\% das escolas brasileiras. Enfim, parece-nos que esta possibilidade de ampliação tem estado na ordem do dia das políticas de escolarização brasileiras.

Nessa direção, faz-se possível perceber que diferentes conjuntos argumentativos têm sido produzidos pela sociedade brasileira visando justificar a implementação dessas novas políticas educacionais. Tais abordagens argumentam sobre uma ressignificação das configurações culturais das famílias brasileiras, pelos novos condicionantes sociais derivados da ocupação do mercado de trabalho pelas mulheres e também pelas restrições normativas ao trabalho infantil, pelos controles políticos das novas demandas coletivas vinculadas ao risco ou à vulnerabilidade social, bem como pela melhoria das condições de qualidade das escolas públicas brasileiras e a consequente melhoria do desempenho nas avaliações de larga escala (CAVALIERE, 2007). 
Assim sendo, de diferentes modos, a ampliação da jornada escolar no Brasil tem perpassado os diferentes programas políticos da última década, fabricando um conjunto de novos sistemas de raciocínio pedagógico que tendem a regular as práticas escolares de nosso país. Vale explicar ainda que, de acordo com Cavaliere e Maurício (2010, p. 2), podemos entender por "jornada escolar ampliada" os casos em que a carga horária ultrapassa as quatro horas diárias, mesmo que apenas em alguns dias da semana.

Especificamente no Estado do Rio Grande do Sul - um dos focos de nossa análise -, no início da década de 1990, observamos a emergência de um conjunto de iniciativas de criação de escolas de tempo integral. Sob a gestão do trabalhista Alceu Collares (1991-1995), foram desenvolvidos no Estado noventa e quatro Centros Integrados de Educação Pública (CIEP), sob inspiração dos modelos produzidos no Rio de Janeiro na gestão de Leonel Brizola (e Darcy Ribeiro). Os referidos centros foram concebidos como estratégias políticas de educação em tempo integral, espaços nos quais os sujeitos escolares permaneceriam por dois turnos, recebendo aspectos tanto da educação formal, como se nomeava na época, quanto da educação informal, que corresponderia aos demais cuidados pedagógicos como a alimentação, atendimento odontológico, projetos comunitários, formação complementar, entre outros.

O desafio posto nessa gramática política era construir escolas de qualidade em bairros pobres, objetivando, conforme um discurso do governador Alceu Colares, "conscientizar que a escola de tempo integral é essencial para a educação com qualidade. Sem ela, jamais conseguiremos competir com os demais países ${ }^{2}$. Entendia-se, naquele momento, que a melhor forma de educar as crianças das comunidades populares era ampliar seu tempo de permanência na escola, perspectiva essa que colaboraria tanto para a formação intelectual desses sujeitos quanto para o desenvolvimento do país. Esse argumento inspirava-se no diagnóstico produzido por Darcy Ribeiro na segunda metade da década de 1980, no qual se indicava a incapacidade dos brasileiros para a educação de sua população (MAURÍCIO, 2004). Nessa direção, caberia às escolas considerar como princípio orientador “o respeito ao universo cultural do aluno no processo de introdução da criança no domínio do código culto. A escola devia servir de ponte entre a cultura do aluno, que sabe muitas coisas para garantir sua sobrevivência, e o conhecimento formal exigido pela sociedade” (MAURÍCIO, 2004, p. 41).

Ainda que a pauta dessa política de escolarização fosse ampla e diversificada, foram inúmeras as críticas sofridas por essa abordagem. Bomeny (2007) sugere que o programa dos CIEPs no Rio de Janeiro produziu inúmeras descontinuidades em sua implementação, tanto no que se refere ao modelo de liderança populista e personalista de Leonel Brizola quanto pela pauta messiânica do projeto que 
presumia um "salvar pela escola". Cavaliere (2007) reconhece nos CIEPs a experiência mais duradoura em educação de tempo integral na história recente de nosso país. Entretanto descreve que, nas experiências da cidade do Rio de Janeiro, pode ser observado um efeito paradoxal do tempo, uma vez que "a ocupação pouco interessante do horário integral levou à criação de um conceito negativo sobre essas escolas e ao seu consequente esvaziamento" (CAVALIERE, 2007, p. 1019). Por outro lado, examinando especificamente uma experiência de CEIP desenvolvida no interior do Rio Grande do Sul, Castro et. al. (2011, online) comentam dimensões exitosas da qualidade pedagógica do trabalho desenvolvido nessa instituição escolar, sobretudo pelas relações políticas desenvolvidas, descritas como "uma escola em que a participação faz a diferença".

No que tange aos processos de seleção e organização do conhecimento escolar nas políticas de ampliação da jornada escolar atualmente implementadas, bem como das concepções de formação humana derivadas, as leituras de Cavaliere (2014) e Libâneo (2014) tornam-se importantes. Cavaliere interroga os limites de tais políticas, quanto ao fato de serem consideradas como compensatórias para determinados segmentos da população. Nessa direção, a ampliação da jornada escolar adquire uma conotação filantrópica, que poderia ser caracterizada por um caráter instável e provisório, ao mesmo tempo em que não posiciona a questão da qualidade da educação no âmbito de uma política de Estado. Complementarmente, a leitura de Libâneo (2014, p. 22) sugere que, na maioria dos casos, a ampliação da jornada escolar é reduzida aos aspectos concernentes ao acolhimento social dos estudantes. Na contramão desta tendência, defende que "privar crianças e jovens do acesso e domínio do conhecimento científico organizado, da cultura, da arte, é praticar exclusão social dentro da escola, antecipando a exclusão social na sociedade".

Para examinarmos a questão na atualidade, a partir de sua agenda múltipla e heterogênea, analisaremos dois conjuntos de práticas curriculares que se propõem a implementar a ampliação da jornada escolar. Atribuiremos atenção ao projeto Escola de Tempo Integral, recentemente implementado no Estado do Rio Grande do Sul, e, ao mesmo tempo, examinaremos a atualização da proposta curricular do Estado de Santa Catarina, que atribui ênfase para a noção de formação integral. Nossa abordagem analítica distancia-se da possibilidade de estabelecer quadros interpretativos baseados na comparação; mas, antes disso, deseja produzir um breve diagnóstico acerca do lugar ocupado pelo conhecimento escolar nas referidas políticas. 


\section{Escola de Tempo Integral: a centralidade das comunidades de aprendizagem}

Em atendimento à Lei estadual n. 14.461, de 16 de janeiro de 2014, o Rio Grande do Sul apresentou uma proposta de reorientação curricular das escolas em tempo integral, assumindo-a enquanto um desafio para o planejamento e a organização das atividades escolares. Parte do pressuposto, em sua argumentação, de que não basta ampliar o tempo de permanência dos estudantes no Ensino Fundamental, "mas sim de reestruturar as bases do tempo/aprendizagem, privilegiando uma formação humanista e de inclusão social” (RIO GRANDE DO SUL, 2014, p. 3). O projeto Escola de Tempo Integral, em sua proposta, busca "a construção das aprendizagens dos estudantes numa jornada escolar ampliada que oferte atividades escolares educativas e diversificadas de forma articulada" (RIO GRANDE DO SUL, 2014, p. 4).

Do ponto de vista teórico, a proposta inspira-se no progressivismo pedagógico, indicando que a possibilidade de formar os sujeitos integralmente é um ideal formativo desde a Paidéia grega. Enaltece, porém, que será na Modernidade que a busca pela emancipação humana destinará a escola pública para este fim. Reconhecendo a experiência desenvolvida no Brasil ao longo do século XX, na qual as propostas de Anísio Teixeira e Darcy Ribeiro adquirem destaque, a documentação pedagógica sugere que o projeto do Estado não pretende organizar-se como "uma justaposição de turnos de trabalho" (RIO GRANDE DO SUL, 2014, p. 7). Será apresentada, então, uma concepção de educação integral posicionada desde um novo prisma formativo:

Propõe-se, assim, uma escola de educação integral que atue como uma comunidade de aprendizagem, na qual os jovens desenvolvam uma cultura democrática, solidária e participativa, por meio do protagonismo em atividades transformadoras, aprendendo a ser autônomo ao formular e ensaiar a concretização de projetos de vida e de sociedade. (RIO GRANDE DO SUL, 2014, p. 7, grifos nossos).

A escola em tempo integral, a partir do processo de implementação em curso no Rio Grande do Sul, pretende produzir uma dimensão formativa que ultrapasse as possibilidades de uma educação escolar baseada na transmissão de conhecimentos. Delineia, nessa direção, a possibilidade de "efetivação de novas atitudes, tanto no que se refere à cognição quanto à convivência social, privilegiando os quatro pilares da Educação adotados pela UNESCO” (RIO GRANDE DO SUL, 2014, p. 11). A formação escolar das crianças e adolescentes do referido contexto, sobretudo aqueles em situação de exclusão, vulnerabilidade social ou privações, adquire, na argumentação desenvolvida, maiores possibilidades de garantia da qualidade social. 
Nesta proposição pedagógica, a escola em tempo integral é posicionada estrategicamente na articulação entre qualidade do ensino e inclusão social. A ampliação da carga horária para oito horas diárias, associada a uma matriz curricular flexível e à participação da comunidade escolar, é uma das apostas evidenciadas na nova política. Acerca desse aspecto, o currículo escolar é dimensionado a partir de novas bases:

A Escola em Tempo Integral, acompanhando o Projeto Político Pedagógico apresentado como marco para a Rede Estadual de Ensino, considera o estudante em seus aspectos biológico e emocional, o qual passa por transformações que dialogam com seu processo de aprendizagem, sendo considerado seu ritmo e especificidades no qual o conhecimento e o currículo se integram e constituem estabelecendo uma ampla rede de significações, reafirmando a escola como lugar de construções e ações coletivas, que passa, necessariamente, pela interlocução, pela escuta de todos os segmentos da Comunidade Escolar. O currículo é interdisciplinar, resgatando o ser em sua unidade e diversidade, no qual a construção do conhecimento perpassa pelo trabalho coletivo, pela cultura de paz e pelo reconhecimento e acolhimento das diferenças dos estudantes. (RIO GRANDE DO SUL, 2014, p. 13, grifos nossos).

O currículo apresentado sob essa orientação pedagógica é fundamentado a partir de quatro fontes, a saber: epistemológica, filosófica, socioantropológica e sociopsicopedagógica. Sob tais bases, o currículo da Escola em Tempo Integral no Estado do Rio Grande do Sul busca contemplar "os processos que se relacionam ao lugar e ao desenvolvimento sustentável, valorizando os saberes locais e os novos conhecimentos e, dessa maneira, resgatando a importância da escola para a comunidade onde está inserida” (RIO GRANDE DO SUL, 2014, p. 14). Acerca dessa perspectiva, podemos inferir a relevância dos saberes e das experiências advindas das comunidades locais, considerando como princípios orientadores do trabalho pedagógico os tópicos expressos no quadro a seguir:

Quadro 1 - Princípios orientadores do trabalho pedagógico

Aspectos que orientam os currículos escolares da Escola em Tempo Integral

- Politecnia e trabalho como princípio educativo;

- Pesquisa como princípio pedagógico;

- Interdisciplinaridade;

- Relação parte-totalidade;

- Relação teoria-prática;

- Reconhecimento de saberes;

- Avaliação emancipatória.

Fonte: Rio Grande do Sul (2014).

Em comum com estes princípios, podemos indicar uma preocupação com três questões específicas. A primeira delas diz respeito ao desenvolvimento de atividades escolares adequadas ao contexto e às demandas comunitárias. Outro aspecto refere-se à promoção de formas alternativas de 
integração curricular que possam favorecer uma articulação entre os diferentes saberes e atividades desenvolvidas na instituição escolar. A terceira questão derivada desta proposta curricular enfatiza a promoção de experiências formativas que desenvolvam os estudantes integralmente.

Do ponto de vista da operacionalização desta proposta curricular, a escola de tempo integral em implementação pelo Estado do Rio Grande do Sul organiza-se a partir de determinadas especificidades. A composição curricular destas escolas ancora-se em metodologias que visam atender às fases do desenvolvimento de cada estudante em uma matriz curricular flexível, capaz de articular a formação geral e as atividades curriculares complementares na organização do espaço, em salas ambientes e no compromisso com a aprendizagem. O documento examinado, em um exercício de proposição de atividades e de saberes a serem ensinados, organiza as aprendizagens necessárias para cada faixa etária, classificadas como infância (6 a 8 anos de idade), segunda infância (9 a 11 anos) e adolescência (12 a 14 anos).

No período referente à infância, por exemplo, o documento indica que as aprendizagens devem contemplar os seguintes aspectos:

Quadro 2 - Aprendizagens necessárias para a infância

\section{Aspectos a serem contemplados}

- A alfabetização e o letramento;

- O desenvolvimento das diversas formas de expressão, que incluem o aprendizado global e interdisciplinar;

- O espaço de apropriação e produção de conhecimento, onde o afeto, a cognição e a ludicidade caminhem juntos e integrados;

- Mobilidade nas salas de aula e atividades que levem os estudantes a explorar mais intensamente as diversas linguagens; da literatura, das artes e a utilizar materiais que ofereçam condições de raciocinar e criar manuseando e explorando as suas características e propriedades.

Fonte: Rio Grande do Sul (2014).

A distribuição das atividades propõe-se a integrar a formação geral com as atividades curriculares eletivas, propondo uma ruptura com a lógica do turno e contraturno. Além das áreas do conhecimento, integram as atividades propostas para Escola de Tempo Integral: iniciação à pesquisa; leitura e produção textual; experiências matemáticas; educação em direitos humanos; arte e cultura; esporte e recreação; orientação de estudos e leituras; e centro de línguas. A articulação entre tais atividades, na proposta pedagógica examinada, toma como objetivo o reconhecimento da escola como um "espaço prazeroso de construção do conhecimento, espelhando a responsabilidade com uma educação de qualidade social, voltada para a inclusão" (RIO GRANDE DO SUL, 2014, p. 26).

Nesse projeto também notamos uma predominância de pressupostos pedagógicos destinados a promover espaços de diálogo e de interlocução, de modo que potencializem a constituição de 
“comunidades de aprendizagem”. Porém diferenciam-se em suas estratégias de intervenção, tanto no que se refere à promoção de ações articuladas entre turno e contraturno quanto na busca da definição de expectativas de aprendizagem para as diferentes faixas etárias. Vale assinalar ainda o privilégio de modelos formativos alicerçados na aprendizagem permanente, nas demandas comunitárias e na integração curricular. De forma geral, também podemos notar uma intensa preocupação com as questões da proteção social da infância, evidenciada recorrentemente. Esse contexto analítico aproxima-se da conclusão de Fabris e Traversini (2011, p. 7, grifos) sobre a escola contemporânea, na qual "os conhecimentos vão ficando para depois, e o foco é atender os sujeitos nos seus danos e prejuízos". A seguir, ampliaremos nossa abordagem para este texto sumarizando algumas balizas teóricas que têm orientado a atualização da proposta curricular do Estado de Santa Catarina.

\section{A atualização da Proposta Curricular de Santa Catarina: os percursos formativos}

No ano de 2014, o Estado de Santa Catarina desenvolveu um processo de atualização de sua proposta curricular (SANTA CATARINA, 2014). Originalmente elaborada entre os anos de 1988 e 1991, a proposta estadual assumiu como base teórica e metodológica a abordagem histórico-cultural, perspectiva também mantida nas atualizações desenvolvidas nos anos de 1998 e $2005^{3}$. Para além de um ajustamento às Diretrizes Curriculares para a Educação Básica (BRASIL, 2010), a proposta catarinense apresenta como novidade um direcionamento para a formação integral na Educação Básica. De acordo com o documento orientador da referida proposta, são três os fios condutores que orientam o processo de atualização.

1) perspectiva de formação integral, referenciada numa concepção multidimensional de sujeito; 2) concepção de percurso formativo visando superar o etapismo escolar e a razão fragmentária que ainda predomina na organização curricular e 3) atenção à concepção de diversidade no reconhecimento das diferentes configurações identitárias e das novas modalidades da educação (SANTA CATARINA, 2014, p. 20, grifos nossos).

Antes de avançarmos na explicitação e análise crítica de cada um destes tópicos, vale assinalar que, de acordo com seus textos orientadores, o processo de reformulação da proposta envolveu professores e gestores da educação básica e das universidades situadas em Santa Catarina. De acordo com o documento examinado, o grupo de trabalho desenvolvido para esta tarefa assumiu como desafio, inclusive, "aproximar o que propõe teórica e metodologicamente das salas de aula e da gestão escolar, ou seja, dialogar diretamente com professores, coordenadores pedagógicos, especialistas e diretores, no 
sentido de contribuir com a reflexão sobre as atuais demandas educacionais em suas práticas pedagógicas" (SANTA CATARINA, 2014, p. 21).

A concepção de formação integral evidenciada na proposta curricular catarinense insere-se no debate nacional em torno das possibilidades de ampliação da jornada escolar, assim do direcionamento das políticas educacionais brasileiras para o atendimento dessa questão. No contexto ora examinado, realiza-se a opção por tratá-la com a noção de "formação humana integral", o que, em uma abordagem histórico-cultural, implica o reconhecimento de que "a busca pela Formação Integral é, portanto, parte da experiência humana, na qual a escolarização vai ocupando lugar central, e a educação é, nesse sentido, expressão do desejo e do direito humano fundamental” (SANTA CATARINA, 2014, p. 25).

Do ponto de vista curricular, a proposta catarinense opta por enfatizar a noção de "currículo integrado", atribuindo com isso centralidade às noções de percursos formativos e de diversidade cultural como princípio educativo. No âmbito da educação integral, defende-se que se trata de "uma estratégia histórica que visa desenvolver percursos formativos mais integrados, complexos e completos, que considerem a educabilidade humana em sua múltipla dimensionalidade" (SANTA CATARINA, 2014, p. 26). Os currículos organizados de forma integrada favoreceriam o desenvolvimento de uma formação abrangente, capaz de ampliar o repertório cultural dos estudantes. Em outras palavras, "os espaços de formação podem/devem se converter em lócus de socialização de saberes, de estudo integrado dos acontecimentos, de iniciação à pesquisa e de incentivo à leitura científica do mundo" (SANTA CATARINA, 2014, p. 26).

A perspectiva histórico-cultural, defendida pela proposta desde suas primeiras versões, requer propostas curriculares que considerem "a possibilidade concreta de ultrapassar as fronteiras do conhecimento e dos saberes" (SANTA CATARINA, 2014, p. 27). Em tais condições, a proposta catarinense apresenta uma relação de aspectos a serem consideradas nas atividades escolares, colocando como pauta para a elaboração dos novos currículos:

- superação do etapismo formativo;

- promoção do diálogo entre as diferentes áreas do conhecimento, sem deixar de considerar as especificidades das áreas e dos componentes curriculares;

- escolhas teórico-metodológicas, de conhecimentos e experiências significativas para compor o percurso formativo e que mobilizem os sujeitos para a aprendizagem;

- reconhecimento da diversidade de identidades e de saberes como condição políticopedagógica para o desenvolvimento da Educação Básica;

- ampliação de espaços de autonomia intelectual e política dos sujeitos envolvidos no percurso formativo;

- exploração das interfaces entre os saberes, dos entrelugares, das redes, das coletividades como lócus geradores de conhecimento; 
- democratização da gestão dos processos educativos pela valorização e fortalecimento do trabalho coletivo (SANTA CATARINA, 2014, p. 27).

Com essa pauta, a proposta catarinense aposta em movimentos de integração curricular, sobretudo entre as áreas do conhecimento. Reconhece, todavia, o posicionamento de dois aportes centrais para o desenvolvimento de seus currículos, a saber: a noção de percurso formativo e a diversidade cultural como princípio educativo. Exploraremos, a seguir, cada uma dessas questões.

O primeiro aspecto orientador da atualização da proposta curricular de Santa Catarina, com vistas à formação integral, refere-se à noção de percursos formativos. A noção indicada é compreendida como "processo constitutivo e constituinte da formação humana" (SANTA CATARINA, 2014, p. 31), associando-se à integralidade do processo educativo de cada um dos estudantes. De acordo com a proposta, requer uma organização curricular, estruturada em práticas pedagógicas, que considere "a importância do desenvolvimento de todas as potencialidades humanas, sejam elas físico/motoras, emocionais/afetivas, artísticas, linguísticas, expressivo-sociais, cognitivas, dentre outras, contribuindo assim para o desenvolvimento do ser humano de forma omnilateral" (SANTA CATARINA, 2014, p. 31). O percurso formativo, então, apresenta-se como o continuum das experiências pelas quais cada estudante, em tempos e espaços apropriados, constrói suas aprendizagens.

A partir do diálogo entre as diferentes formas de conhecimento, no âmbito da Educação Básica, os percursos seriam delineados na busca de "apropriação, compreensão e produção de novos conhecimentos" (SANTA CATARINA, 2014, p. 32). Adquire relevância o papel do professor na condução das atividades propostas:

Uma atividade é orientadora porque o professor parte do pressuposto de que o resultado final da aprendizagem é fruto das ações negociadas e tem consciência de que não domina o conjunto de fenômenos da sala de aula e da turma. Por isso ele elege uma orientação geral que possibilita saber a direção a ser seguida. O professor é o organizador da atividade e por isso sabe o que está em jogo no espaço da sala de aula: os conceitos e os conteúdos que permitem sua apropriação, as principais dificuldades em apreendê-los, as respostas que indicam se o conteúdo está sendo aprendido ou não, e as ações necessárias para redirecionar a busca de um nível mais avançado de conhecimento. (SANTA CATARINA, 2014, p. 32).

Mantendo sua vinculação com a teoria histórico-cultural, a atualização da proposta catarinense segue apostando na dimensão conceitual para a formação dos estudantes. Mais que isto, sob a lógica da formação integral, encaminha como finalidade do trabalho pedagógico a ampliação do repertório cultural dos estudantes. Em outras palavras, reconhece que "é por meio da apropriação cultural, mediada pela linguagem, em suas diferentes formas, que os sujeitos em sua singularidade se 
humanizam” (SANTA CATARINA, 2014, p. 34). Inspirada em autores como Vygotsky e Davidov, objetivamente, reitera a importância da elaboração conceitual.

A opção por uma noção de percurso formativo que atenda às demandas dos estudantes e dos projetos escolares busca promover "a efetivação de um processo de formação integral dos sujeitos relacionada a uma organização escolar que oportunize à escola ser e fazer aquilo que lhe dá identidade e autoridade para desempenhar a sua função social" (SANTA CATARINA, 2014, p. 41). Para tanto, o trabalho pedagógico deverá ser orientado por um currículo cuja proposta de educação integral seja “ampliar o repertório vivencial da vida escolar dos sujeitos, buscando relacionar os conceitos sistematizados às vivências na comunidade" (SANTA CATARINA, 2014, p. 44).

O segundo aspecto orientador da proposta curricular catarinense é o posicionamento da diversidade como princípio formativo. Partindo da ideia de Educação Básica como um direito de todos, a proposta curricular pontua duas dimensões para essa garantia, a saber: a educação comum e o direito à diferença. A articulação dessas dimensões, de maneira geral, é a forma escolhida para desenvolver uma educação pertinente a um contexto de democratização. Reconhecendo a polissemia concernente à noção de diversidade, o texto analisado explicita alguns sentidos predominantes.

A diversidade como "característica da espécie humana” é o primeiro sentido apresentado. Partese do pressuposto de que os "seres humanos são diversos em suas experiências de vida históricas e culturais, são únicos em suas personalidades e são também diversos em suas formas de conceber o mundo" (SANTA CATARINA, 2014, p. 54). Outro sentido evidenciado posiciona a diversidade como heterogeneidade, vinculada a um reconhecimento das diferenças:

A diversidade está relacionada com as aspirações dos grupos humanos e das pessoas de viver em liberdade e no exercício de sua autodeterminação, como também à aspiração da vida em democracia e à necessidade de vivenciar coletivamente as realidades sociais que são múltiplas e de lutar pelo reconhecimento dos direitos humanos e a respeitá-los. Portanto, a valorização das diferenças étnicas e culturais, por exemplo, não significa aderir aos valores do outro, mas respeitá-los como expressão da diversidade de todo ser humano, sem qualquer discriminação. (SANTA CATARINA, 2014, p. 54).

A abordagem proposta para a temática da diversidade sugere a compreensão das identidades e das diferenças enquanto construções sociais que promovam uma escola inclusiva e democrática. Associa-se também, de acordo com a proposta catarinense, à defesa de uma "educação multicultural" (SANTA CATARINA, 2014, p. 55), o que representaria o entendimento da formação integral - ênfase do documento - como estratégia de enfrentamento dos discursos tolerantes ou pressupostos homogeneizadores. 
Do ponto de vista curricular, ao considerar as diretrizes nacionais para a Educação Básica, a proposta apresenta uma relação de temáticas a serem colocadas em discussão:

[...] a educação para as relações de gênero; a educação para a diversidade sexual (orientação sexual e identidade de gênero); a educação e prevenção; a educação ambiental formal; a educação das relações étnico-raciais; e as modalidades de ensino: a educação especial; a educação escolar indígena; a educação do campo e a educação escolar quilombola. (SANTA CATARINA, 2014, p. 57).

A diversidade como princípio educativo, então, sugere uma redefinição dos projetos escolares, de maneira que estejam abertos às expressões identitárias e, ao mesmo tempo, afirmem os direitos civis, sociais e políticos dos estudantes. Do ponto de vista da formação integral, "um exemplo do direito à igualdade na questão pedagógica é reconhecer a capacidade universal de aprender de todos como ponto de partida e compreender que existem diferenças nos processos de aprendizado dos estudantes" (SANTA CATARINA, 2014, p. 90). Em linhas gerais, podemos indicar que a concepção de formação integral colocada em ação na proposta curricular do Estado de Santa Catarina atribui ênfase às noções de percursos formativos e de diversidade cultural.

\section{Considerações finais}

Ao longo do presente texto, procuramos examinar os modos pelos quais as políticas de ampliação da jornada escolar, atualmente em evidência no contexto brasileiro, mobilizam os seus processos de seleção e organização do conhecimento escolar. Tanto o Estado do Rio Grande do Sul quanto o de Santa Catarina direcionaram esforços pedagógicos nessa direção, evidenciando preocupações com a educação de qualidade social e com o processo formativo integral das crianças e jovens.

No contexto do Rio Grande do Sul, no âmbito da política curricular examinada, notamos uma prioridade na constituição de comunidades de aprendizagem, ora centradas em habilidades genéricas, ora definidas pela construção de expectativas de aprendizagem para as etapas do desenvolvimento humano. Em Santa Catarina, por outro lado, sob inspiração das teorizações histórico-culturais, privilegiou-se um tratamento dos percursos formativos dos sujeitos escolares, associados pedagogicamente a um tratamento da diversidade cultural. Em comum às propostas, percebemos um direcionamento para o atendimento das demandas individuais dos estudantes, ora definidas por suas expectativas de aprendizagem, ora associadas aos delineamentos de seus percursos formativos.

Cabe esclarecer, na finalização deste texto, que fizemos uso de uma concepção de conhecimento escolar que reconhece sua relevância social e política para a democratização da educação pública. 
Como sugerem Gabriel e Ferreira (2012) em abordagem contemporânea, embora situado em um campo controverso, o conhecimento escolar ainda serve para pensar a escolarização, desde que situado em outras articulações. Buscando essas articulações, juntamente com Moreira (2013, p. 14), entendemos que é preciso que a instituição escolar, "além de ensinar conhecimentos que melhor expliquem o mundo (o que certamente precisa fazer), procure subsidiar e comprometer o aluno em direção a esforços pela mudança deste mundo". O conhecimento na escola, nessa concepção, apresenta-se como uma questão curricular central, tanto de ordem epistemológica quanto de justiça social.

A abordagem sociológica de Michael Young (2013), anteriormente apreciada neste artigo, permite-nos estreitar a aproximação com a objetividade do conhecimento a ser ensinado nas escolas:

Eu suponho que a questão do currículo "qual conhecimento?" é tanto uma questão epistemológica que define o que deve constituir o direito dos estudantes em estágios diferentes e em áreas de especialização diferentes, como uma questão de justiça social sobre o direito ao conhecimento por parte de todos os alunos sem se levar em consideração se o conhecimento é rejeitado ou considerado difícil. Se algum conhecimento é "melhor", como podemos negá-lo a todos os alunos e permitir que alguns, como fazemos na Inglaterra, sejam limitados ao "conhecimento sem poder" a partir da idade de 14 ou 16? (YOUNG, 2013, p. 20).

A retomada do conhecimento escolar, no debate curricular atual, traz implicações significativas para as práticas de ampliação da jornada. Como lembram-nos Gabriel e Cavaliere (2012, 292), ainda que as formas escolares estejam em crise, "isso não significa que ela já tenha sido condenada e esvaziada de qualquer possibilidade de subversão”. Nossas ponderações acerca do currículo da educação integral, ainda conforme as autoras, inclinam-se a entender "o currículo escolar não como algo imutável, e reconhecer que os conteúdos não são objetos estáveis e universais, tampouco uma adaptação didatizada do conhecimento científico, mas construções específicas, tanto do ponto de vista político como epistemológico" (GABRIEL; CAVALIERE, 2012, p. 292). Nessa direção, ao dirigirmos nossas preocupações para as políticas de ampliação da jornada escolar em implementação nos Estados do Rio Grande do Sul e de Santa Catarina, optamos por estreitar nossos vínculos com uma concepção centrada na relevância política e epistemológica do conhecimento escolar em nossos currículos, vislumbrando suas potencialidades na ampliação do repertório cultural de nossos estudantes.

\section{Notas}

${ }^{1}$ Esse entendimento é ampliado nos estudos de Silva (2014) e Silva (2015).

${ }^{2}$ Cf.: <http://www.pdt.org.br/index.php/nossas-bandeiras/educacao/mais-sobre-os-cieps/os-cieps-do-rio-grande-dosul>.

3 Para o exame das políticas curriculares desenvolvidas no Estado de Santa Catarina, são importantes as contribuições de Thiesen $(2007,2011)$. 


\section{REFERÊNCIAS}

BOMENY, Helena. Salvar pela escola: programa especial de educação. Sociologia, problemas $e$ práticas, Braga, n. 55, p. 41-67, 2007.

BRASIL. Diretrizes curriculares nacionais gerais para a Educação Básica. Brasília: MEC, 2010.

CABALLO, Maria Belén; CARIDE, José Antonio; GRADAÍLlE, Rita. Entre los tiempos escolares y los tiempos de ocio: su incidencia en la vida cotidiana de los adolescentes que cursan la Educación Secundaria obligatoria en España. Educar em Revista, Curitiba, n. 45, p. 37-55, 2012.

CASTRO, Marta Luz Sisson; SOUZA, Magda Vianna de; WERLE, Flávia Obino Corrêa; MORAIS, Vera Rosane Silveira. Escola Estadual Neusa Mari Pacheco: a Scholl Where Participation Makes a Difference. JISTE. Journal of the International Society for Teacher Education, Aarhus, v. 15, p. 76-81, 2011.

CATARSI, Enzo. Tempo pieno: pieno di che? Riflessioni ciariane a partire dall'esperienza "rottiggiana". In: CATARSI, Enzo (Org.). La scuola a tempo pieno in Italia: una grande utopia. Pisa: Edizioni del Cerro, 2004. p. 13-30. v. 1.

CAVALIERE, Ana Maria. Escola pública de tempo integral no Brasil: filantropia ou política de Estado? Educação e Sociedade, Campinas, v. 35, n. 129, p. 1205-1222, 2014.

CAVAliERE, Ana Maria. Tempo de escola e qualidade na educação pública. Educação e Sociedade, Campinas, v. 28, n. 100, p. 1015-1035, 2007.

CAVALIERE, Ana Maria; MAURICIO, Lúcia Velloso. A ampliação da jornada escolar nas regiões Nordeste e Sudeste: sobre modelos e realidades. In: REUNIÃO ANUAL DA ANPED, 33. Caxambu/MG, 17 a 20 de outubro de 2010. Anais eletrônicos... Rio de Janeiro: Anped, 2010. p. 1-16. Disponível em: <http://33reuniao.anped.org.br/33encontro/app/webroot/files/file/Trabalhos\%20em\%20 PDF/GT13-6913--Int.pdf>. Acesso em: 30 set. 2017.

COELHO, Lígia Martha Coimbra da Costa. História(s) da educação integral. Em Aberto, Brasília, v. 22, n. 80, p. 83-96, 2009.

FABRIS, Elí Terezinha Henn; TRAVERSINI, Clarice Salete. Conhecimentos escolares sob outras configurações: efeitos das movimentações disciplinares e de controle. REUNIÃO ANUAL DA ANPED, 34. Natal/RN, 2 a 5 de outubro de 2011. Anais eletrônicos... Rio de Janeiro: Anped, 2011. p. 1-16. Disponível em: <http://34reuniao.anped.org.br/images/trabalhos/GT13/GT13-1243\%20int.pdf>. Acesso em: 30 set. 2017.

FELICIO, Helena Maria dos Santos. Análise curricular da escola de tempo integral na perspectiva da educação integral. E-curriculum, São Paulo, v. 8, n. 1, p. 1-18, 2012.

FORQUIN, Jean-Claude. Escola e cultura: as bases sociais e epistemológicas do conhecimento escolar. Porto Alegre: Artmed, 1993. v. 1. 
FORQUIN, Jean-Claude. Saberes (organização dos). In: VAN ZANTEN, Agnès (Coord.). Dicionário de Educação. Petrópolis: Vozes, 2011. p. 714-719. v. 1.

GABRIEL, Carmen Teresa; FERREIRA, Márcia Serra. Disciplina escolar e conhecimento escolar: conceitos sob rasura no debate curricular contemporâneo. In: LIBANEO, José Carlos; ALVES, Nilda (Orgs.). Temas de pedagogia: diálogos entre didática e currículo. São Paulo: Cortez, 2012. p. 227-241. v. 1.

GABRIEL, Carmen Teresa; CAVALIERE, Ana Maria. Educação integral e currículo integrado: quando dois conceitos se articulam em um programa. In: MOLL, Jaqueline (Org.). Caminhos da educação integral no Brasil: direito a outros tempos e espaços educativos. Porto Alegre: Penso, 2012. p. 277-294. v. 1.

LIBÂNEO, José Carlos. Escola de tempo integral em questão: lugar de acolhimento social ou de ensino-aprendizagem? In: BARRA, Valdeniza (Org.). Educação: ensino, espaço e tempo na escola de tempo integral. Goiânia: Cegraf, 2014. p. 4-39. v. 1.

MASSCHELEIN, Jan; SIMONS, Maarten. A pedagogia, a democracia, a escola. Belo Horizonte: Autêntica, 2014. v. 1.

MAURICIO, Lucia Velloso. Literatura e representações da escola pública de horário integral. Revista Brasileira de Educação, Rio de Janeiro, n. 27, p. 40-56, 2004.

MOLL, Jaqueline. A agenda da educação integral: compromissos para sua consolidação como política pública. In: MOLL, Jaqueline (Org.). Caminhos da educação integral no Brasil: direito a outros tempos e espaços educativos. Porto Alegre: Penso, 2012. p. 129-146. v. 1.

MOORE, Rob. Social Realism and the problem of the problem of knowledge in the sociology of education. British Journal of Sociology of Education, London, v. 34, n. 3, p. 1-21, 2012.

MOREIRA, Antônio Flávio Barbosa. A importância do conhecimento no currículo e os pontos de vista de Michael Young. In: FAVACHO, André Márcio Picanço; PACHECO, José Augusto; SALES, Shirlei Rezende (Orgs.). Currículo, conhecimento e avaliação: divergências e tensões. Curitiba: CRV, 2013. p. 33-47. v. 1

MOREIRA, Antonio Flávio Barbosa. Os princípios norteadores de políticas e decisões curriculares. Revista Brasileira de Política e Administração Educacional, Porto Alegre, v. 28, n. 1, p. 180-194, 2012.

PACHECO, José Augusto. Educação, formação e conhecimento. Porto: Porto, 2014. v.1.

POPKEWITZ, Thomas. El cosmopolitismo y la era de la reforma escolar. Madrid: Morata, 2009. v. 1.

RIO GRANDE DO SUL. Documento orientador para a reestruturação curricular das escolas em tempo integral - ensino fundamental. Porto Alegre: SEE, 2014.

SANTA CATARINA. Proposta curricular de Santa Catarina: formação integral na Educação Básica. Florianópolis: SEE, 2014. 
SILVA, Roberto Rafael Dias da. Políticas de integração curricular para o Ensino Médio no Brasil contemporâneo: um estudo no programa Ensino Médio Inovador. ETD - Educação Temática Digital, Campinas, v. 17, n. 2, p. 252-270, 2015.

SILVA, Roberto Rafael Dias da. Políticas de constituição do conhecimento escolar para o Ensino Médio no Rio Grande do Sul: uma analítica de currículo. Educação em Revista, Belo Horizonte, v. 30, n.1, p. 127-158, 2014.

SILVA, Roberto Rafael Dias da; PEREIRA, Ana Luiza. Políticas de constituição do conhecimento escolar na pesquisa educacional brasileira. Cadernos de Pesquisa, São Paulo, v. 43, n. 150, p. 884-905, 2013.

TEIXEIRA, Anísio Spínola. Pequena introdução à filosofia da educação. São Paulo: Nacional, 1978. v. 1.

THIESEN, Juares da Silva. Análise da constituição da proposta curricular de Santa Catarina pela perspectiva do ciclo de políticas. Cadernos de Educação, Pelotas, n. 40, p. 157-175, 2011.

THIESEN, Juares da Silva. Vinte anos de discussão e implantação da proposta curricular de Santa Catarina na rede de ensino: desafios para um currículo de base histórico-cultural. PerCursos, Florianópolis, v. 8, n. 2, p. 41-54, 2007.

YOUNG, Michael. A superação da crise em estudos curriculares: uma abordagem baseada no conhecimento. In: FAVACHO, André Márcio Picanço; PACHECO, José Augusto; SALES, Shirlei Rezende (Orgs.). Currículo, conhecimento e avaliação: divergências e tensões. Curitiba: CRV, 2013, v.1, p. 11-31. 
Between training paths and learning communities: a study of curriculum policies

for comprehensive education in Southern Brazil

\begin{abstract}
This article examines the processes of implementation of curriculum policies to expand the school day developed in the Rio Grande do Sul and Santa Catarina states. By signing up in the field of Curriculum Studies, sought to understand their selection processes and organization of school knowledge. Policies are implemented from two distinct and complementary concepts, namely: training courses and learners communities. It was found through a textual analysis of the guiding curriculum documents of these policies, a significant concern with the knowledge of school selection processes to be taught; however, also noted some difficulties to indicate the guiding criteria for these choices and pedagogical rationales to justify their implementation.
\end{abstract}

Keywords: Curriculum policies. Integral education. School knowledge.

Roberto Rafael Dias Silva

E-mail: robertoddsilva@yahoo.com.br
Entre trayectorias formativas e comunidades de aprendizaje: un estudio de las políticas curriculares para la educación integral en el Sur de Brasil

\section{Resumen}

En este trabajo se analiza la implementación de políticas curriculares de ampliar la jornada escolar desarrolladas en el Rio Grande do Sul y Santa Catarina. Al suscribirse en el campo de los estudios curriculares, trató de comprender sus procesos de selección y organización del conocimiento escolar. Las políticas se implementan a partir de dos conceptos distintos y complementarios, a saber: trayectorias formativas y comunidades de aprendizaje. Se encontró a través de un análisis textual de los documentos curriculares de estas políticas, una preocupación significativa con el los procesos de selección conocimiento para enseñar. Sin embargo, también señaló algunas dificultades para indicar los criterios rectores de estas opciones y fundamentos pedagógicos para justificar su ejecución.

Palabras clave: Políticas curriculares. Educación integral. Conocimiento escolar.

Enviado em: 01-04-2016

Versão final recebida em:

Aprovado em: 01/04/2017 